
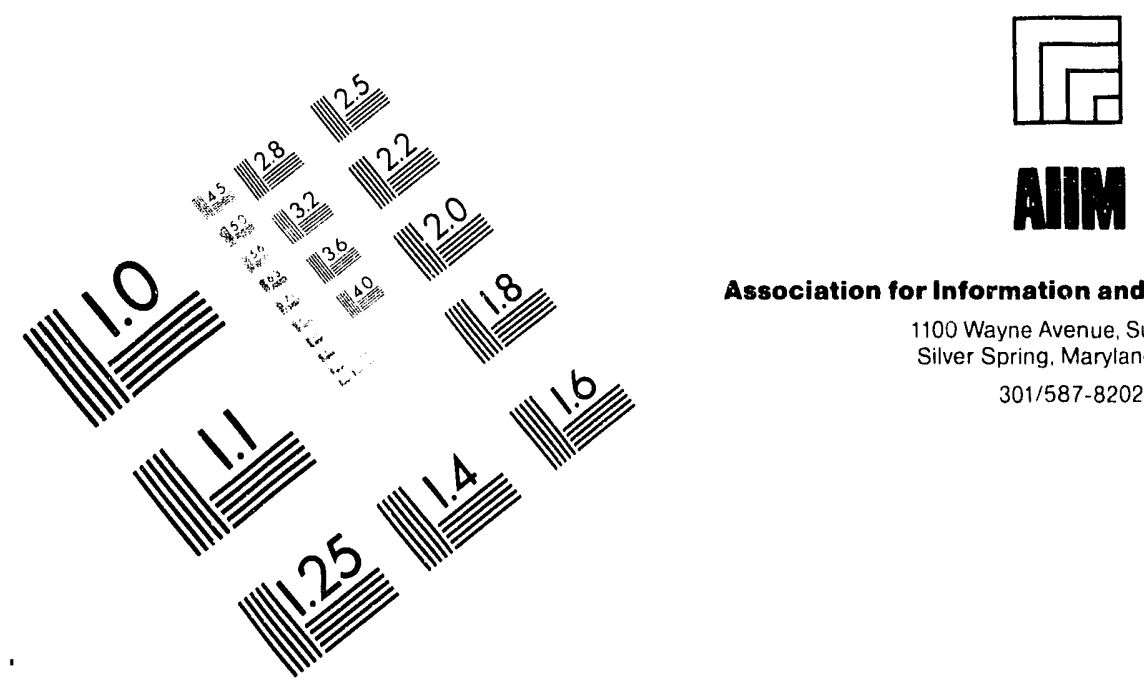

Association for Information and Image Management

1100 Wayne Avenue, Suite 1100

Silver Spring. Maryland 20910

301/587-8202

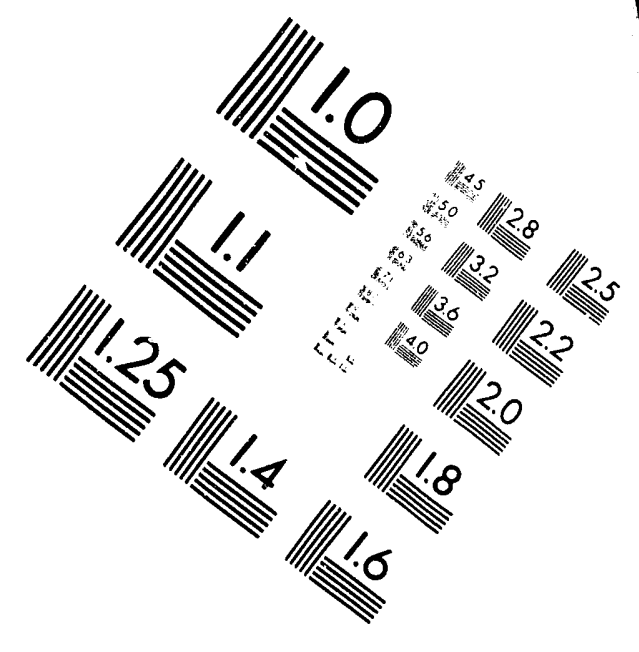

Centimeter

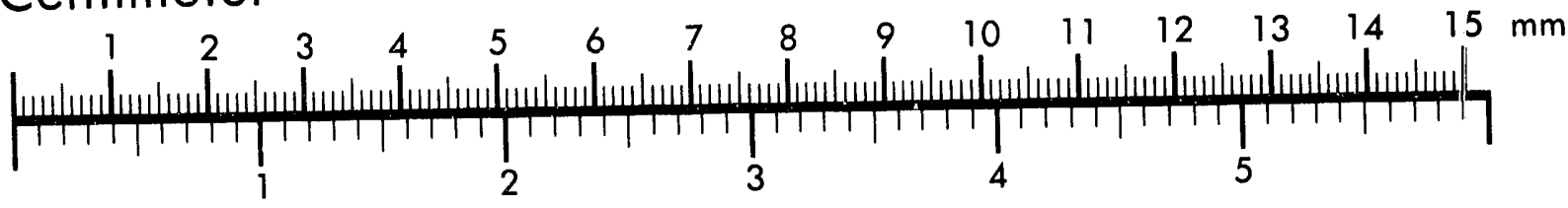
Inches
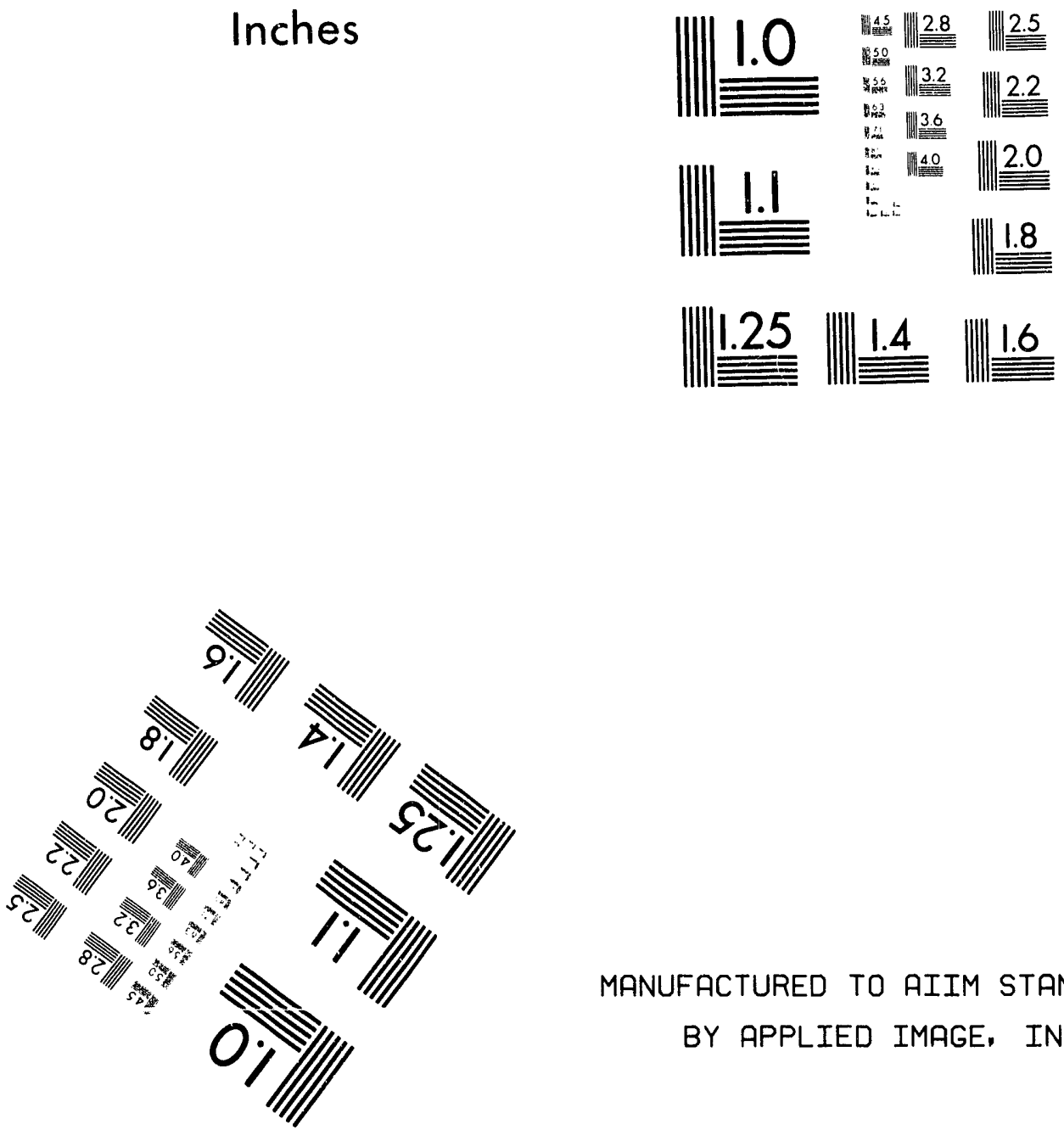

MANUFACTURED TO AIIM STANDARDS

BY APPLIED IMAGE, INC.

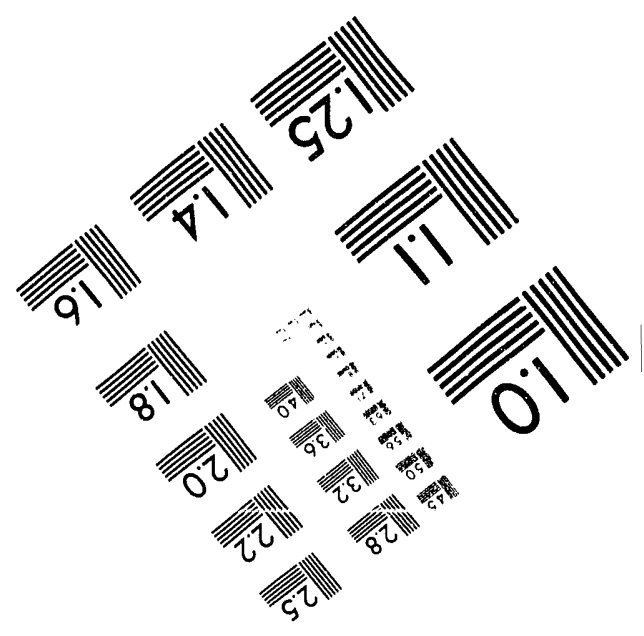



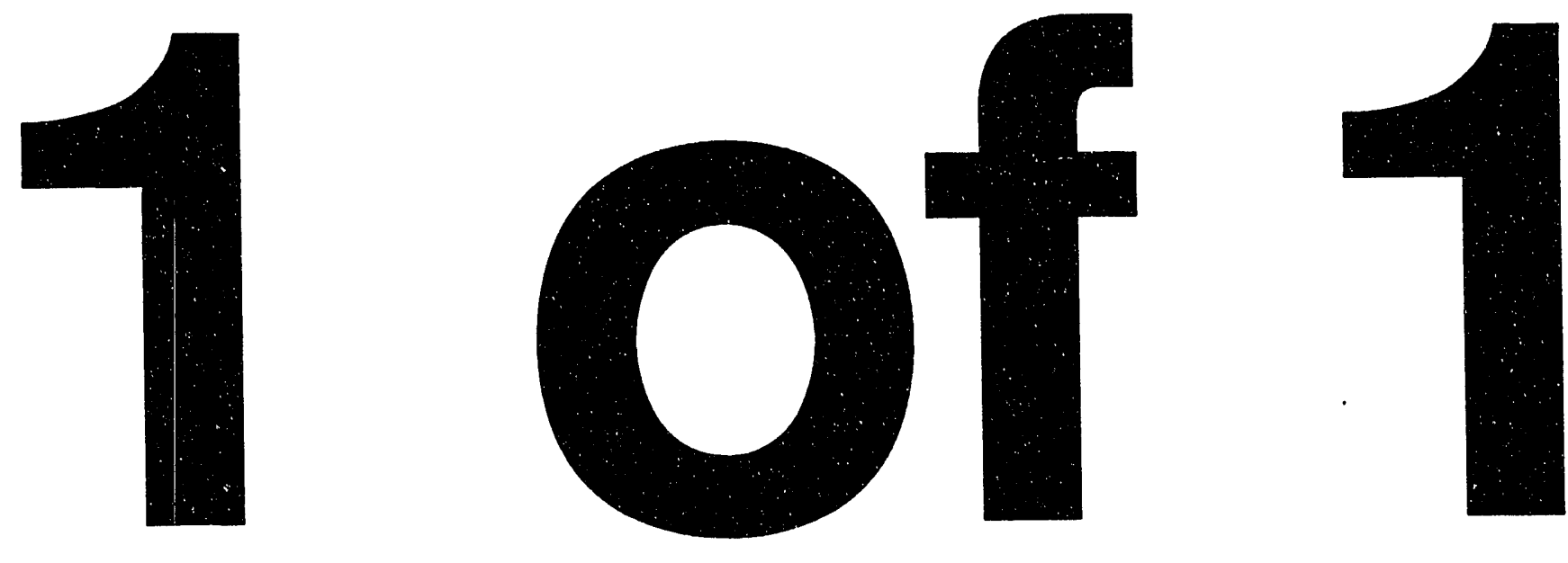


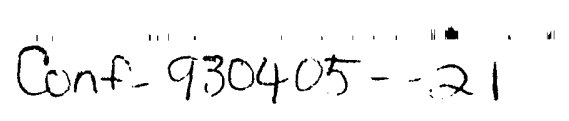

EGG 10617-2186

UC-701

\title{
GROWTH OF SINGLE CRYSTALS OF MERCURIC IODIDE ON THE GROUND AND IN SPACE*
}

\author{
L. van den Berg \\ EG\&G Fnergy Measurements, Inc., Santa Barbara Operations \\ 130 Robin Hill Road, Goleta, CA
}

\begin{abstract}
A short review will be given of the methods by which mercuric iodide is prepared and purified to obtain material suitable for the growth of single crystals. The method used in our laboratory to grow single crystals up to 1,000 grams in weight from the vapor will be discussed. The effects of gravity on the growth process will be described.

A crystal growth system suitable for operation in the reduced gravity environment of space has been designed, and crystal growth experiments have been performed during the flights of spacelab 3 (April 1985) and the International Microgravity Laboratory (January 1992). The structural quality and electronic properties of the ground-based and the space-grown crystals have been compared, and the results will be presented.
\end{abstract}

\section{INTRODUCTION}

Large single crystals of mercuric iodide are presently grown routinely on the ground. (Fig. 1) The crystal growth process introduces in the crystals several types of defects which have a negative effect on the performance of detectors fabricated from these crystals.

The probability exists that these defects are caused by the effects of gravity on the crystal growth process. Gravity can cause slip in the crystal when it is very soft at the growth temperature. In addition, gravity can cause irregular convection in the growth ampoule. This leads to irregular growth rates and the incorporation of defects in the crystals.

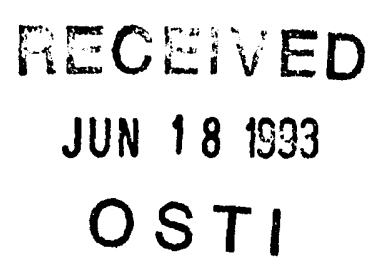

*The submitted manuscript has been authored by a contractor of the U.S. Government under Contract No. DE-AC08-88NV10617. Accordingly, the U.S. Government retains a nonexclusive, royalty-free license to publish or reproduce the published form of this contribution, or allow others to do so, for U.S. Government purposes. 


\section{EXPERIMENTAL SETUP}

On the basis of the erystal growth technology developed on the ground, a furnace was designed which could be accommodated in a spacelab rack. (Figs. 2, 3) The basic operation of the furnace is the same as the ground-based furnaces. Two crystal growth experiments have been performed with this equipment: One on Spacelab 3 (April - May 1985) and one on IML-1 (January 1992).

\section{RESULTS}

The space-grown crystals have been subjected to gamma ray diffraction to establish the overall structural quality: and in addition, the electronic properties have been measured so that they could be compared with those of ground-grown crystals.

\section{Gamma Ray Rocking Curves}

The gamma ray rocking curve experiments have been performed at the University of Missouri, Columbia, Missouri. The presence of a research reactor at that institution permits the availability of relatively short-lived isotopes.

The rocking curve results for the Spacelab 3 crystal are shown in Fig. 4. The crystal gives essentially a single peak, indicating a homogeneous crystal. This can be compared with the rocking curve for a ground-grown crystal, which shows two separate peaks (Fig. 5), indicating that the crystal exists of two separate parts with a large misorientation between the parts.

The rocking curves for the IML-1 crystal have been measured with more sophisticated equipment which had higher resolution. The gamma ray beam was moved across the face of the crystal, and the (002) diffraction peak was carefully monitored. The results are shown in Fig. 6. The crystal still shows a defective region (double peak) but the widths of the peaks are much narrower than for the Spacelab 3 crystal.

\section{Electronic Measurements}

The electronic measurements performed on detectors made from the spacelab 3 crystal showed that the mobility of the holes was significantly greater for the space crystal. (Fig. 7) This can be ascribed to the higher structural quality of the crystal, since the material form which the crystal was grown was the same as that used for the groundgrown crystals.

Similar results are expected for the IML-1 crystal. 


\section{SUMMARY}

The growth of high-quality crystals in space indicates strongly that mobilities of the holes can be improved by increasing the structural quality of the crystals. The task now at hand is to mimic the zero gravity conditions on the ground.

\section{DISCLAIMER}

of work sponsored by an agency of the United States This report was prepared as an account of work sponsor any agency thereof, nor any of their Government. Neither the United States Government implied, or assumes any legal liability or responsiemployees, makes any warranty, express or implied, of any information, apparatus, product, or bility for the accuracy, completeness, or usefulness of any infinge privately owned rights. Referprocess disclosed, or represents that its use would not inf or service by trade name, trademark, ence herein to any specific commercial product, process, or ser imply its endorsement, recommanufacturer, or otherwise does not necessarily constitute or any agency thereof. The views mendation, or favoring by the United States Governmentarily state or reflect those of the

and opinions of authors expressed herein do not
United States Government or any agency thereof. 


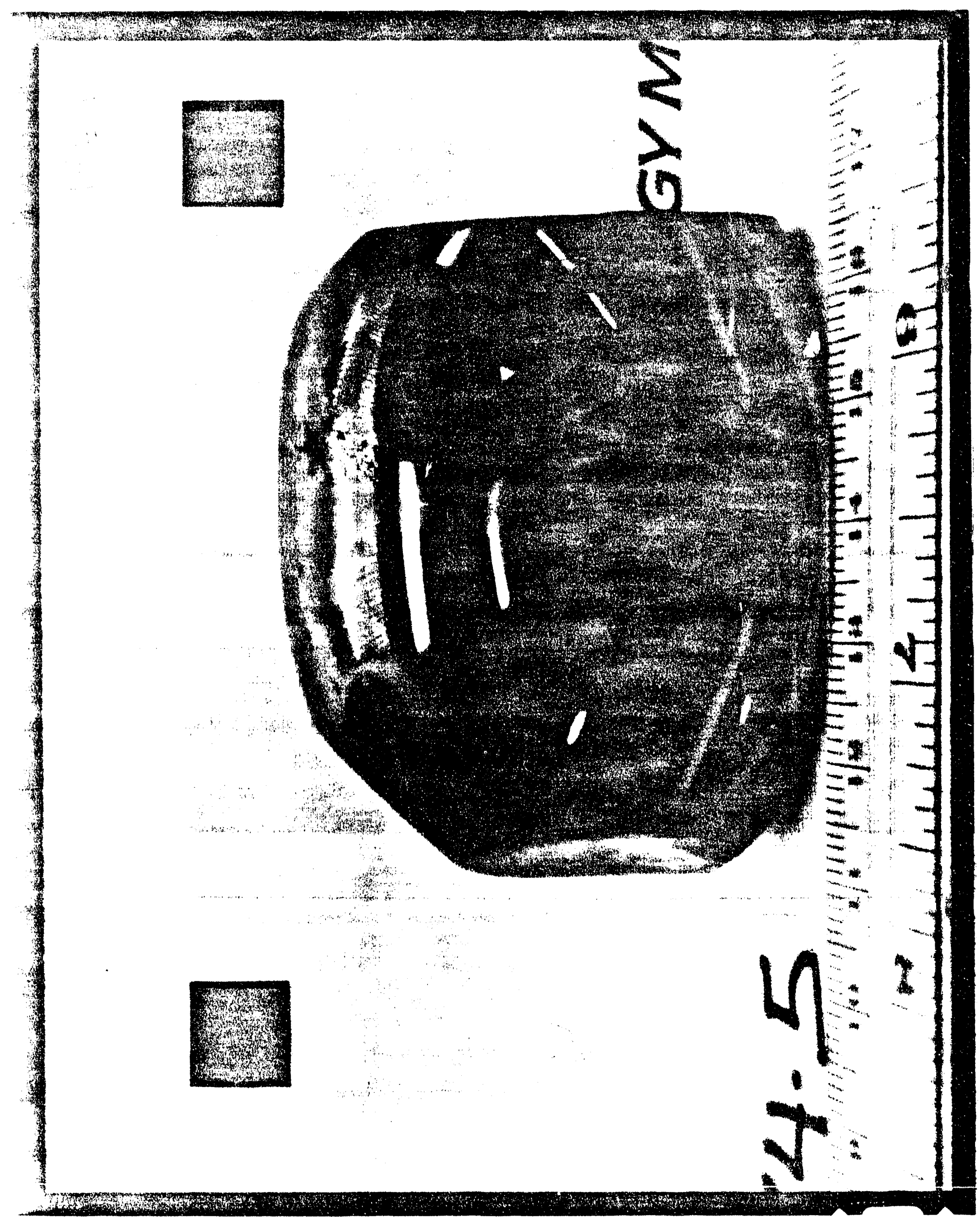




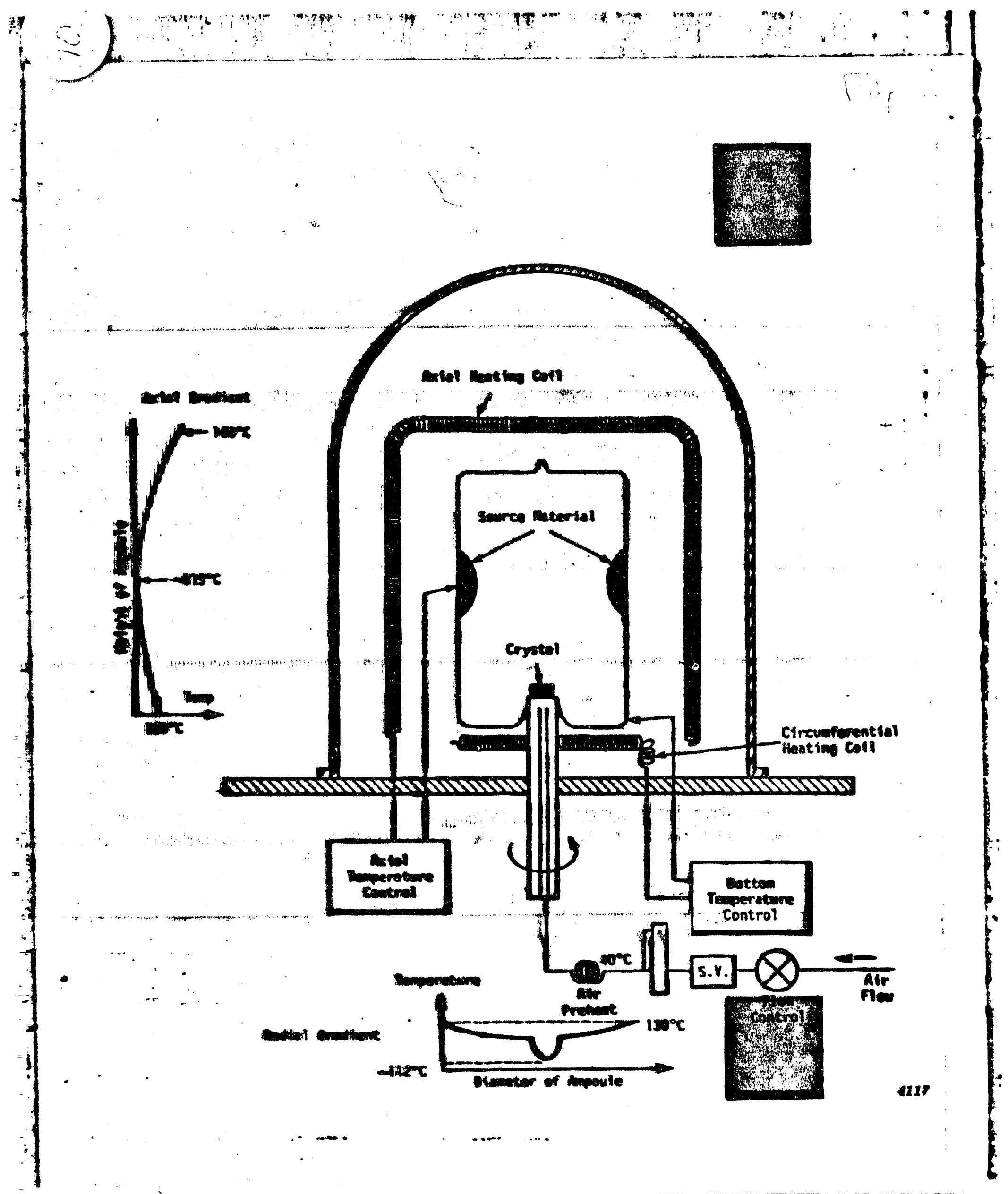




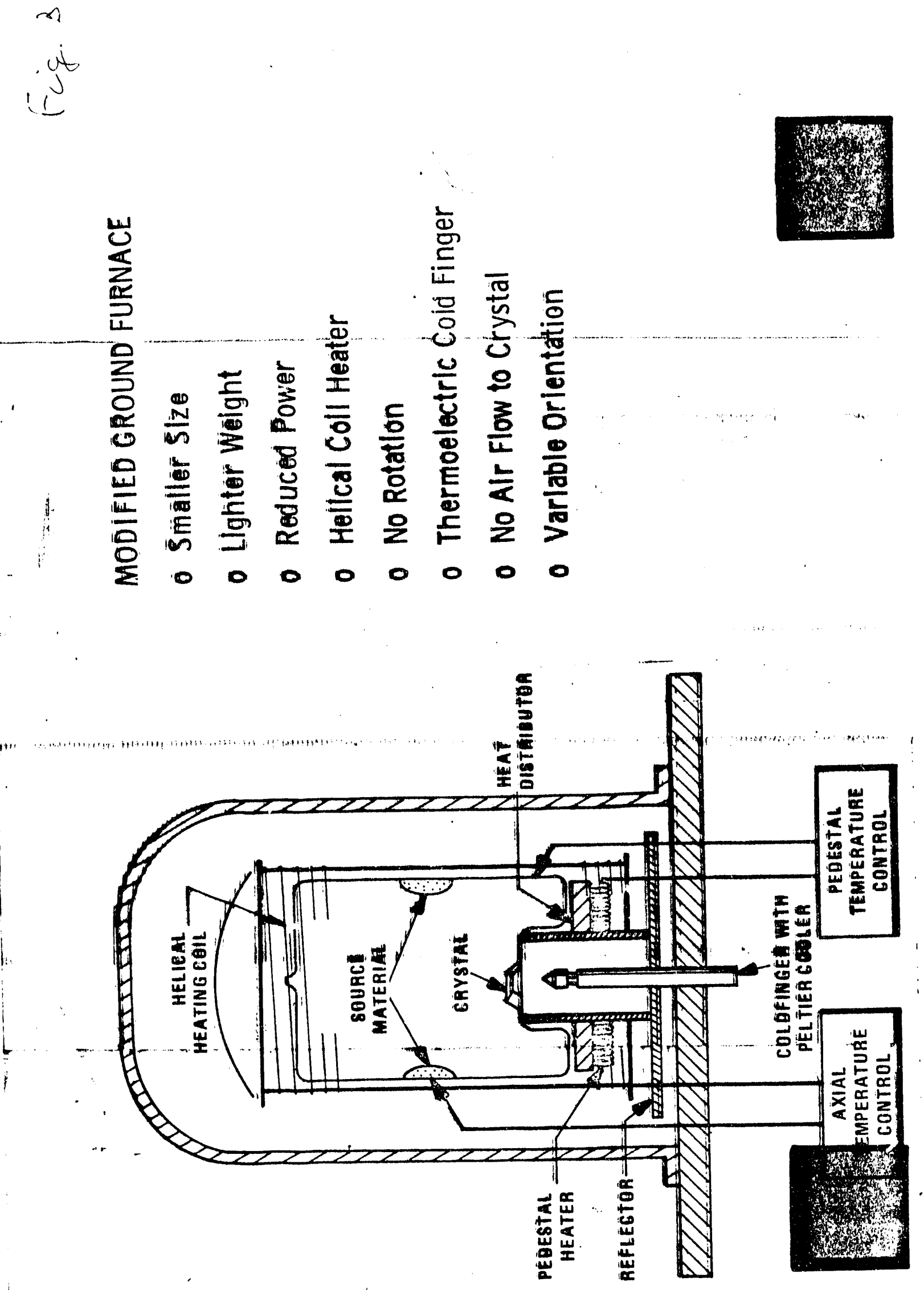



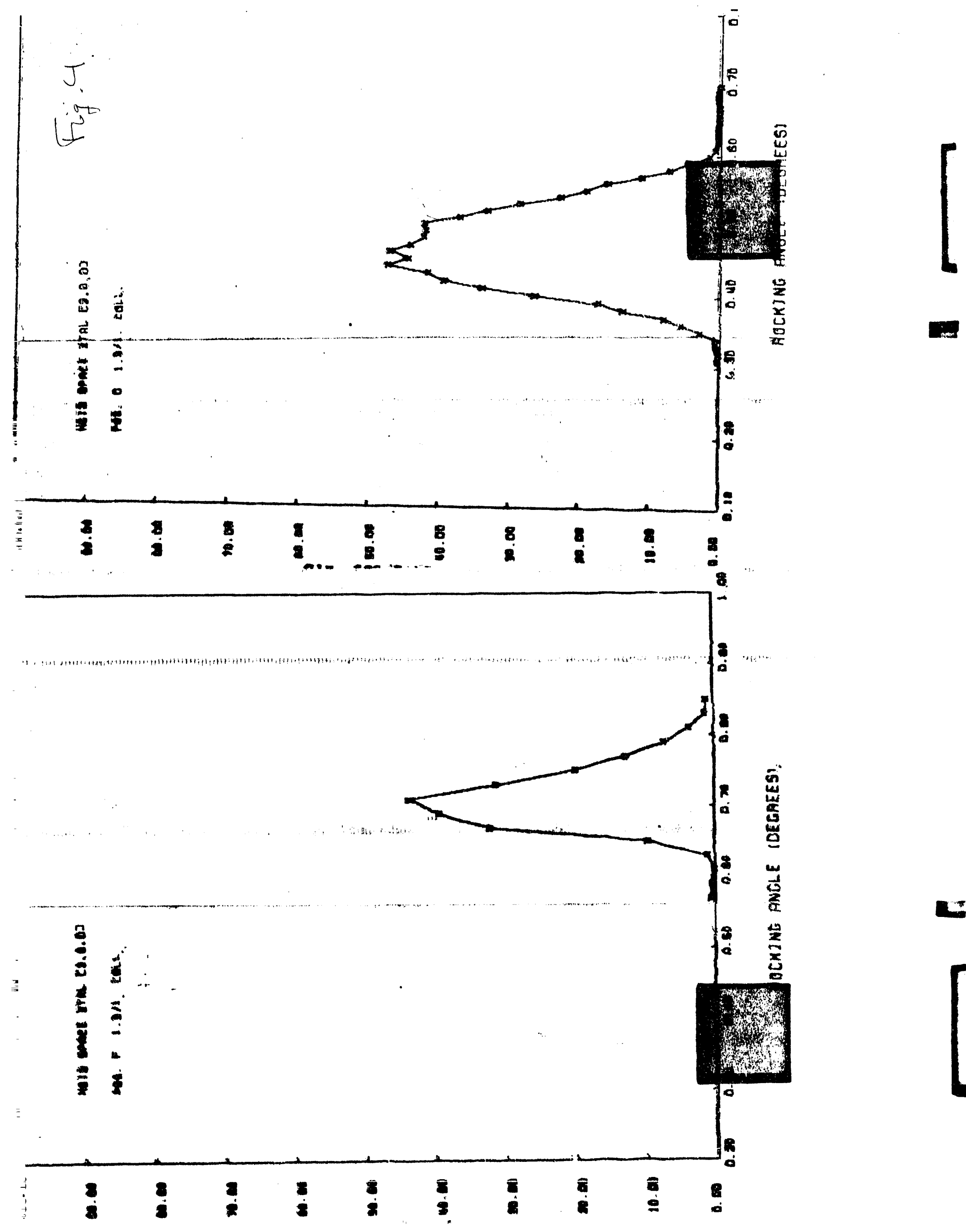
Fig. 5

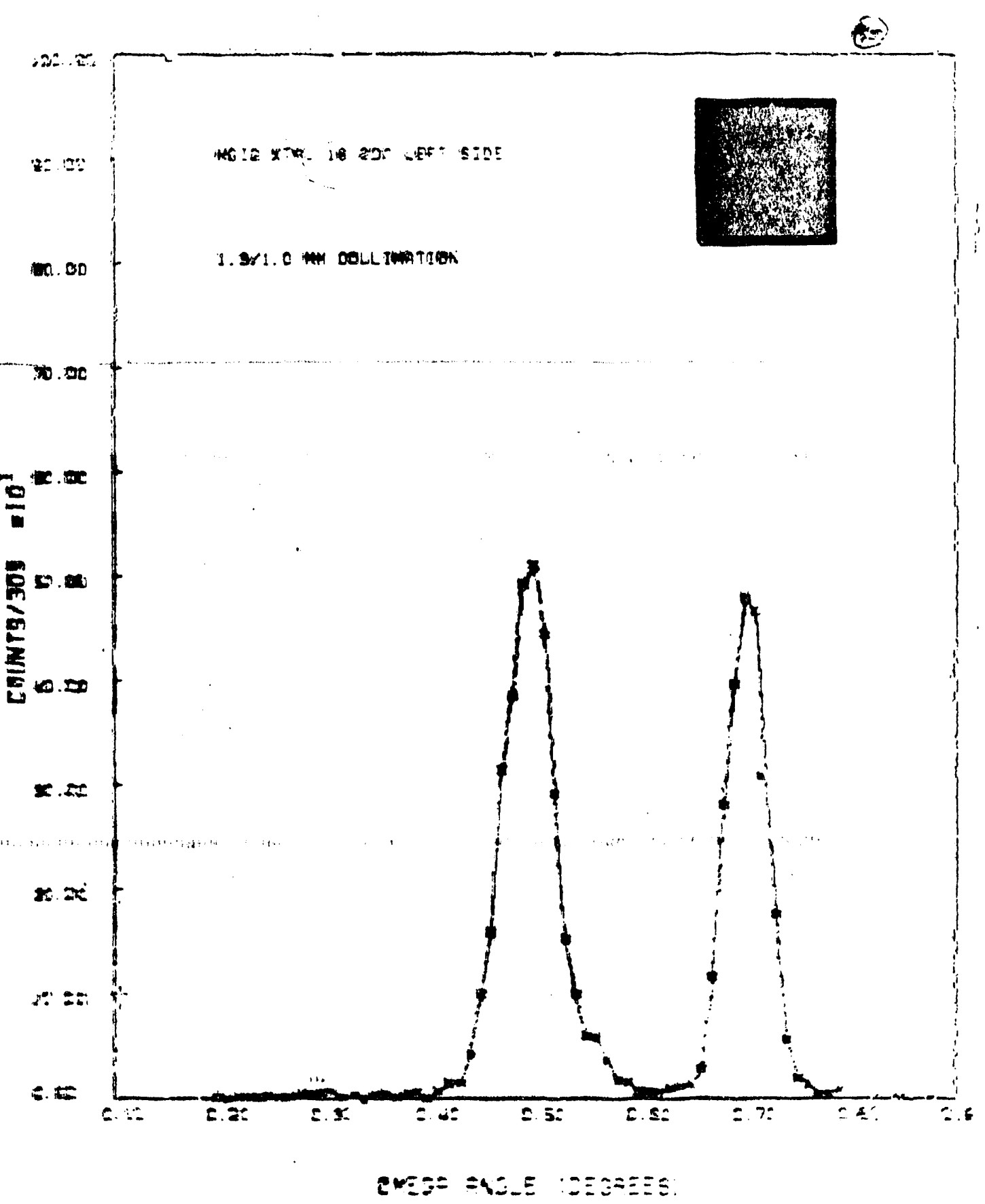


$i^{0}$

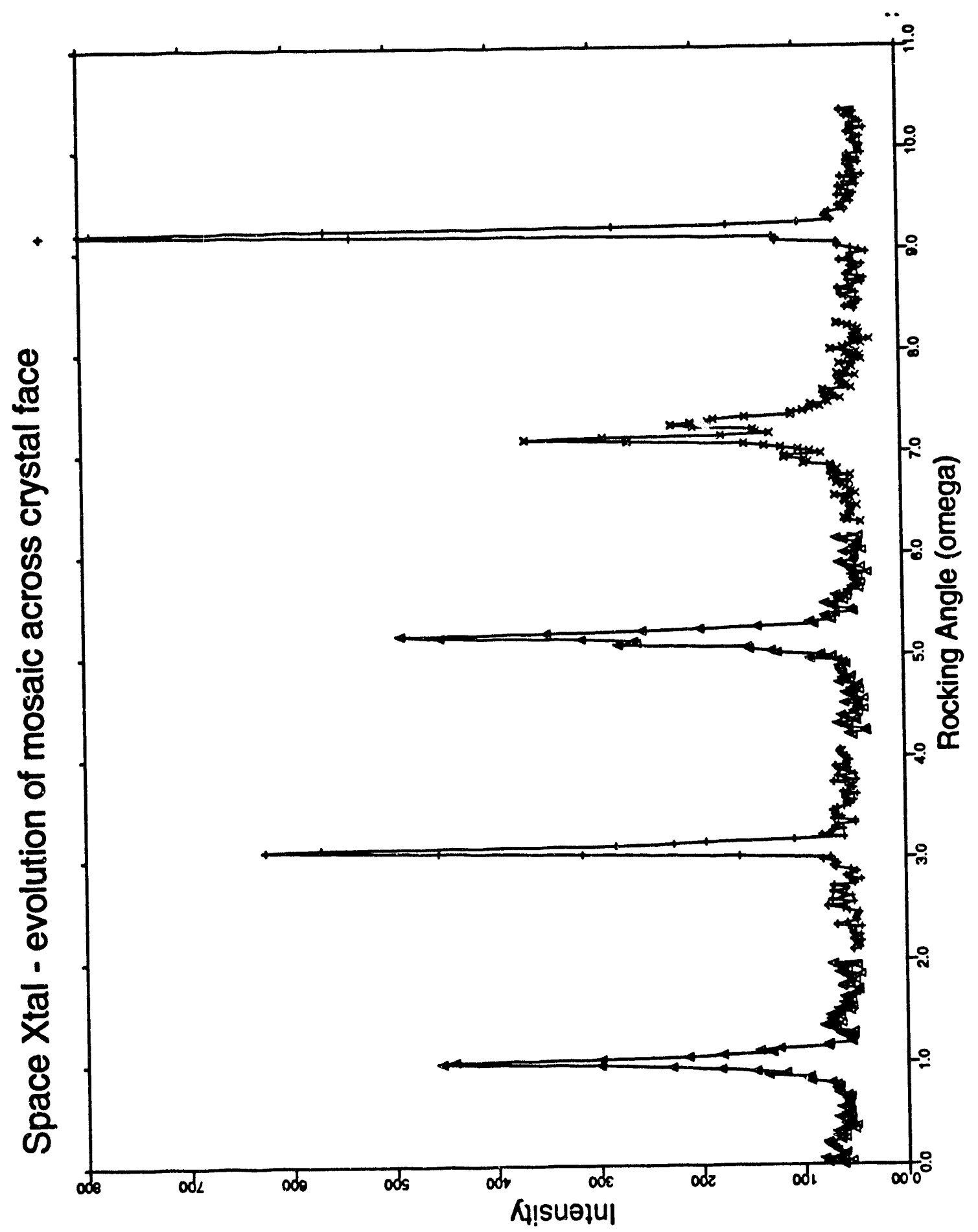




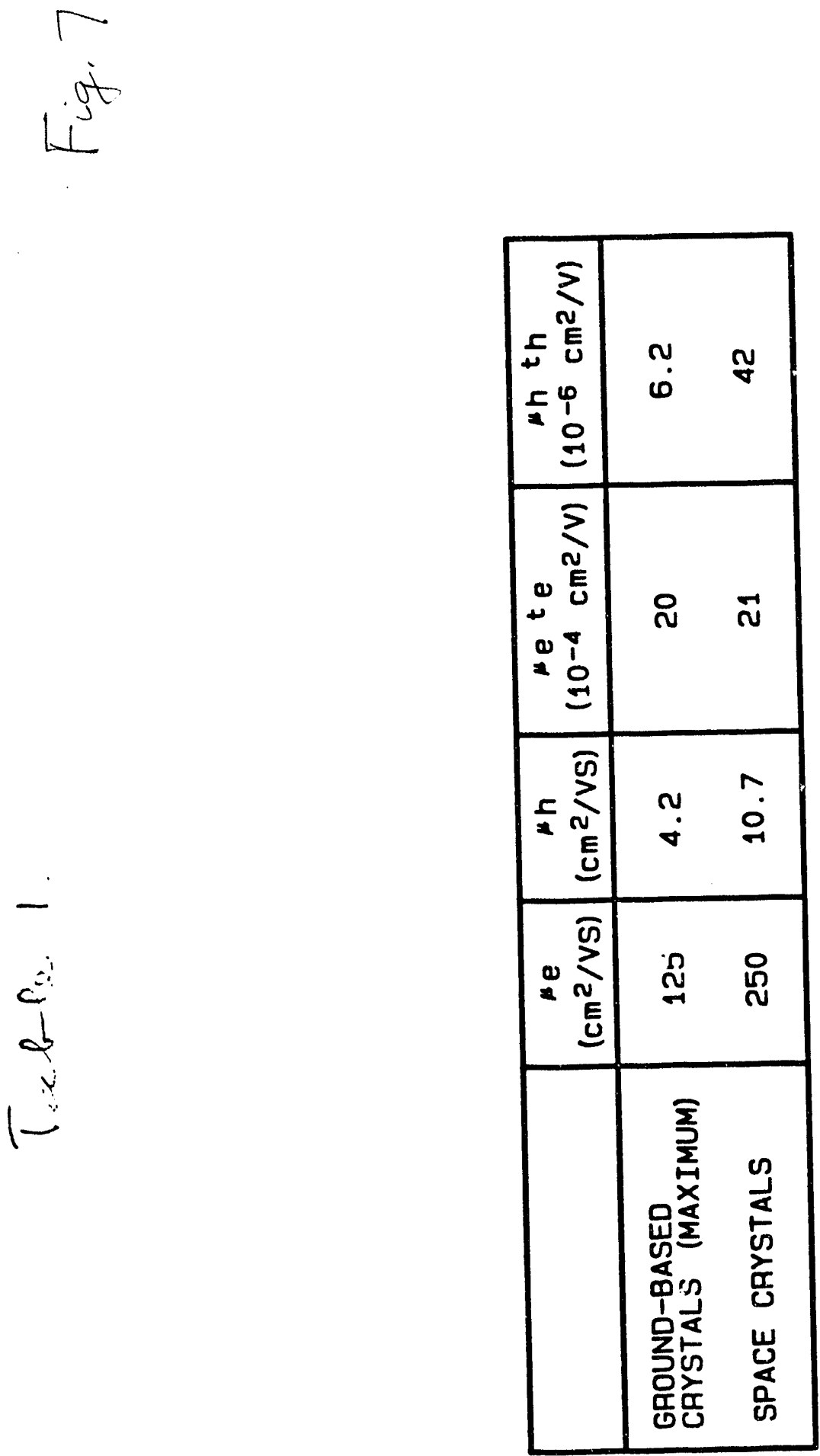



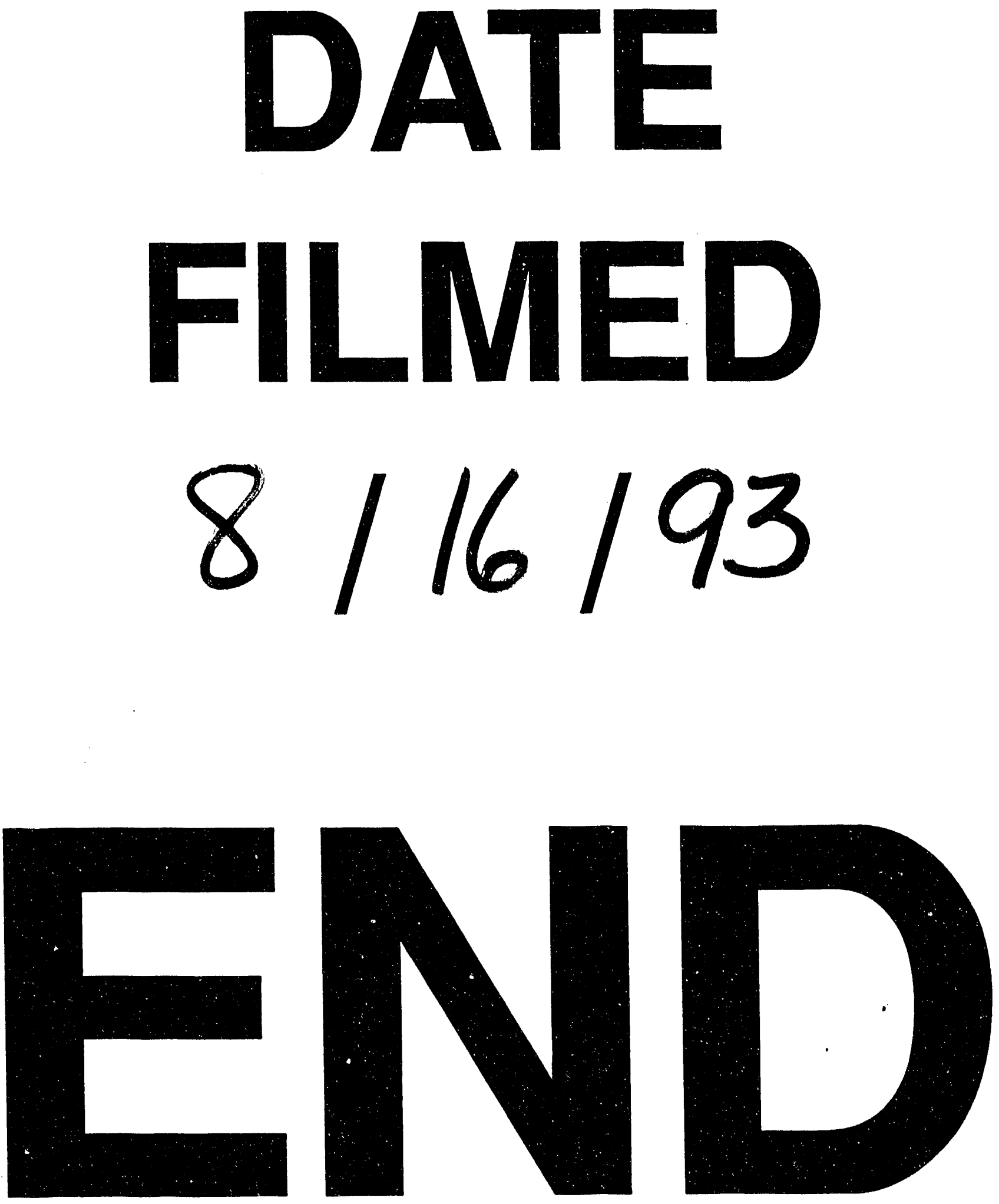